\title{
A ORIGEM DAS BORDAS DE MIRMEQUITA NOS XENOCRISTAIS DE FELDSPATO POTÁSSICO EM ROCHAS MÁFICAS E HÍBRIDAS DO MACIÇO SANTA ANGÉLICA - ES
}

\author{
Marcela Lopes Zanon ${ }^{1}$, Alexandre de Oliveira Chaves ${ }^{2}$, Caio Vinícius Turbay Gabrig ${ }^{3}$ \\ 1 - Programa de Pós-graduação em Geologia da UFMG, Instituto de Geociências, 31270-901; Avenida Antônio Carlos, 6627, 31270-901, \\ Pampulha, Belo Horizonte, MG. zanon.marcela@yahoo.com.br \\ 2 - Departamento de Geologia e Centro de Pesquisa Prof. Manoel Teixeira da Costa, IGC, UFMG. Avenida Antônio Carlos, 6627, 31270-901, \\ Pampulha, Belo Horizonte, MG.alochaves@yahoo.com.br \\ 3 - Universidade Federal do Espírito Santo, Campus Alegre, Caixa Postal: 16, Alto Universitário, s/n, 29500-000, Alegre, ES. turbay@cca.ufes.br
}

Recebido em 14 de setembro de 2012; aceito em 5 de fevereiro de 2013

\begin{abstract}
Resumo: O Complexo Intrusivo Santa Angélica faz parte de um dos mais importantes plútons de magmatismo bimodal da Suíte G5, gerada no estágio pós-colisional ( 530 - $490 \mathrm{Ma}$ ) da Orogênese Brasiliana, esta que deu origem ao Orógeno Araçuaí-Ribeira. Este corpo intrusivo é representado por litotipos félsicos e máficos, sendo estes separados por uma extensa zona de mistura de magmas onde ocorrem rochas híbridas. O estudo petrográfico microscópico de rochas máficas e híbridas com xenocristais de K-feldspato indicou bordas de reação nestes grãos constituídas exclusivamente por mirmequita. A fim de compreender quais reações xenocristal-líquido desencadearam a formação destas bordas mirmequíticas, foram realizadas análises em microssonda que, posteriormente foram interpretadas juntamente ao estudo petrográfico microscópio. Os resultados indicaram que as porções máficas e híbridas ainda estavam em estado líquido quando houve a migração dos xenocristais que, ao reagirem com o material magmático, desencadearam uma reação envolvendo íons de Ca e Na resultando na formação de uma borda constituída por mirmequita.
\end{abstract}

Palavras-chave: Santa Angélica, mirmequita, xenocristal.

Abstract: THE ORIGIN OF MIRMEKITIC BORDERS IN K-FELDSPAR XENOCRYSTALS FROM MAFIC AND HYBRID ROCKS OF SANTA ANGÉLICA MASSIVE - ES - The Santa Angelica Intrusive Complex is part of the more importants plutons of the G5 Suite of bimodal magmatism, intrudet in the post-collisional (530 - $490 \mathrm{Ma}$ ) of the Brasiliano orogeny that made the Orogen Araçuaí-Ribeira. This pluton is represented by felsic and mafic rocks, which are separated by an extensive zone of magma mixing and mingling with the occurrence of hybrid rocks. The petrographic study of the hybrid and mafic rocks with K-feldspar xenocrysts indicates their edges reaction consist exclusively of mirmekite. In order to understand how xenocristal-liquid reactions triggered the formation of these edges, microprobe analyzes were performed, These data and microscopic results were interpreted together. The results indicated that when the xenocrysts migrated to the mafic and hybrids rocks they were still in the liquid state, resulting in the reaction between the xenocrysts and the Ca and $\mathrm{Na}$ ions of the magma that formatted the myrmekite edge.

Keywords: Santa Angelica, myrmekite, xenocristal.

\section{INTRODUÇÃO}

O Complexo Intrusivo Santa Angélica (CISA) corresponde a um corpo intrusivo de aproximadamente $200 \mathrm{~km}^{2}$, localizado na região sul do Espírito Santo, entre os municípios de Alegre, Cachoeiro de Itapemirim e Castelo (Figura 1). Ele faz parte da chamada Suíte G5 gerada durante o estágio pós-colisional (530 - $490 \mathrm{Ma}$ ) da Orogênese Brasiliana, quando o Cinturão Araçuaí-Ribeira atingiu seu estágio de relaxamento termal, possibilitando a geração de magmas de origem mantélica e crustal (Pedrosa-Soares \& Wiedemann-Leonardos 2000). As rochas do CISA estão representadas por litotipos félsicos (granito) e máficos (diorito e gabro), sendo estes separados por uma extensa zona de mistura de magmas onde ocorrem rochas híbridas.

As rochas máficas e híbridas (formadas por magma mixing e mingling) do CISA sistematicamente apresentam xenocristais de K-feldspato. O estudo petrográfico microscópico indicou bordas de reação nos xenocristais constituídas exclusivamente por mirmequita. $O$ objetivo deste trabalho é compreender a reação magma-xenocristal que desencadeou a formação da mirmequita, bem como os fatores que condicionam este processo, com o auxílio de análises químicas de minerais em microssonda eletrônica em perfis traçados da borda de reação até o centro dos grãos de K-feldspato.

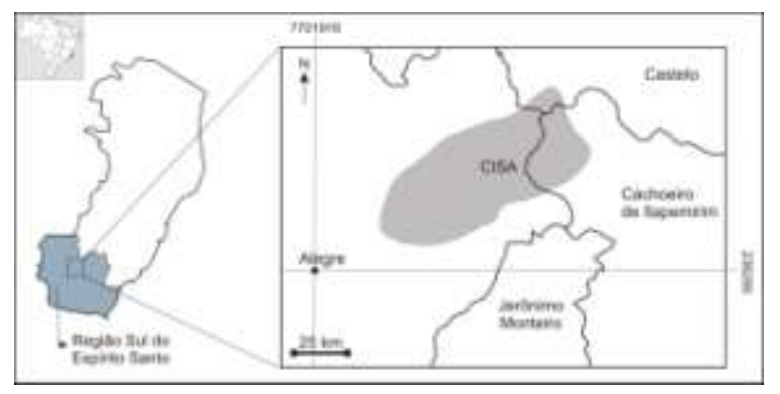

Figura 1 - Mapa regional da área de estudo. O Complexo Intrusivo Santa Angélica (CISA) está inserido nos municípios de Alegre, Cachoeiro de Itapemirim e Castelo, na região sul do Espírito Santo (adaptado do Mapa Geológico Regional do Geobank www.geobank.sa.cprm.gov.br). 


\section{CONTEXTO GEOLÓGICO REGIONAL}

A Orogênese Brasiliana é caracterizada pela colisão entre os crátons São Francisco-Congo, Kalahari e Paraná-Rio de La Plata, que resultou na edificação de uma extensa cadeia de montanhas neoproterozóica denominada Província Mantiqueira (Almeida et al., 1997; Brito-Neves et al., 1991). Este sistema orogênico que se estende por toda a região sul e sudeste do Brasil divide-se nos orógenos São Gabriel, Dom Feliciano, Brasília Meridional, Ribeira e Araçuaí.

Os orógenos Araçuaí e Ribeira, também conhecidos como Cinturão Neoproterozoico AraçuaíRibeira (Pedrosa-Soares et al., 2001) (Figura 2), abrangem principalmente os estados do Espírito Santo, Rio de Janeiro e São Paulo. A definição do limite entre estes orógenos tem sido proposta desde 1977, por Almeida, e ainda encontra-se em discussão até o presente momento. Pedrosa-Soares \& Wiedemann-Leonardos (2000) denominaram como orógeno Araçuaí a região localizada entre a borda leste do cráton São Francisco e o oceano Atlântico, entre os paralelos $15^{\circ}$ e $21^{\circ} \mathrm{S}$, com trend estrutural $\mathrm{N}-\mathrm{S}$. Já do paralelo $21^{\circ}$ até $25^{\circ} \mathrm{S}$, onde as estruturas adquirem orientação NE-SW, o orógeno passa a ser chamado de Ribeira (Machado et al, 1996; Ebert \& Hasui, 1998). A área de estudo situase próximo ao limite entre estes orógenos, onde ocorre a inflexão do trend estrutural regional de N-S para NE-SW.

De acordo com os estágios magmáticos associados à evolução geotectônica do Cinturão Araçuaí-Ribeira definidos por Pedrosa-Soareas et al. (1999), e conforme apresentado na introdução deste artigo, o Complexo Intrusivo Santa Angélica (CISA) faz parte da Suíte G5, gerada na fase pós-colisional (530 - $490 \mathrm{Ma})$ da orogênese Brasiliana (Wiedemann et al., 1986; Bayer et al., 1987). Na região sul do Espírito Santo, esta suíte é representada por vários plutons com composição granítica e núcleos gabróicos que caracterizam o estágio de relaxamento termal do orógeno e a origem híbrida resultante da mistura de magmas mantélicos e crustais (Wiedemann, 1993; Pinto et al., 1997, 2001; Pedrosa-Soares \& WiedemannLeonardos, 2000; Wiedemann-Leonardos et al., 2000; Noce et al., 2000; Medeiros et al., 2001; Pedrosa-Soares et al., 2001, 2006; Wiedemann et al., 2002; Campos et al., 2004; Martins et al., 2004; Mendes et al., 2005; Silva et al., 2005). Comumente apresentam feições de mistura mecânica (mingling) e química (mixing) de magmas, além de enclaves máficos e xenólitos das rochas encaixantes.

O CISA (Figura 3) apresenta composição bimodal caracterizada por um zonamento inverso concêntrico, formado pela alternância de rochas félsicas (monzonitos a granitos) nas bordas e por dois núcleos de composição máfica (dioritos a gabros), sendo que o contato entre estas rochas é marcado por uma extensa zona de mistura de magmas (magma mingling e mixing) (SchmidtThomé e Weber-Diefenbach, 1987; Bayer et al., 1987; Wiedemann et al., 1987, Wiedemann et al., 1997, Wiedemann-Leonardos et al., 2000). As bordas deste corpo intrusivo são marcadas por uma foliação que apresenta a mesma direção do trend regional (NE/SW), com mergulho subvertical (Bayer et al., 1987).

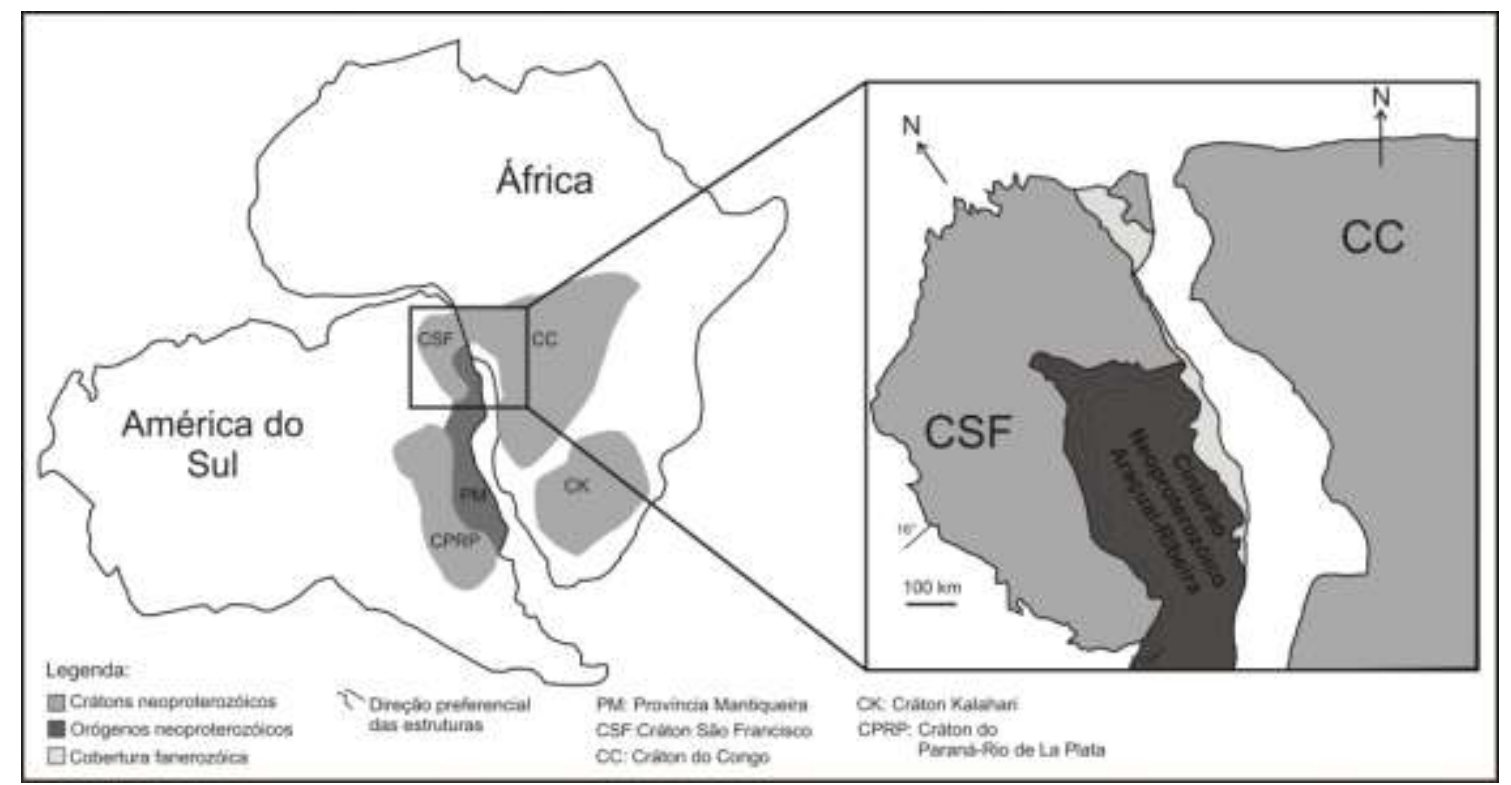

Figura 2 - Província Mantiqueira, com destaque para porção central e setentrional, o Cinturão Neoproterozoico Araçuaí-Ribeira (Adaptado de Alkmin et al., 2006 e Pedrosa-Soares et al., 2007). 


\section{Mapa Geológico do Complexo Intrusivo Santa Angélica e de suas rochas encaixantes}

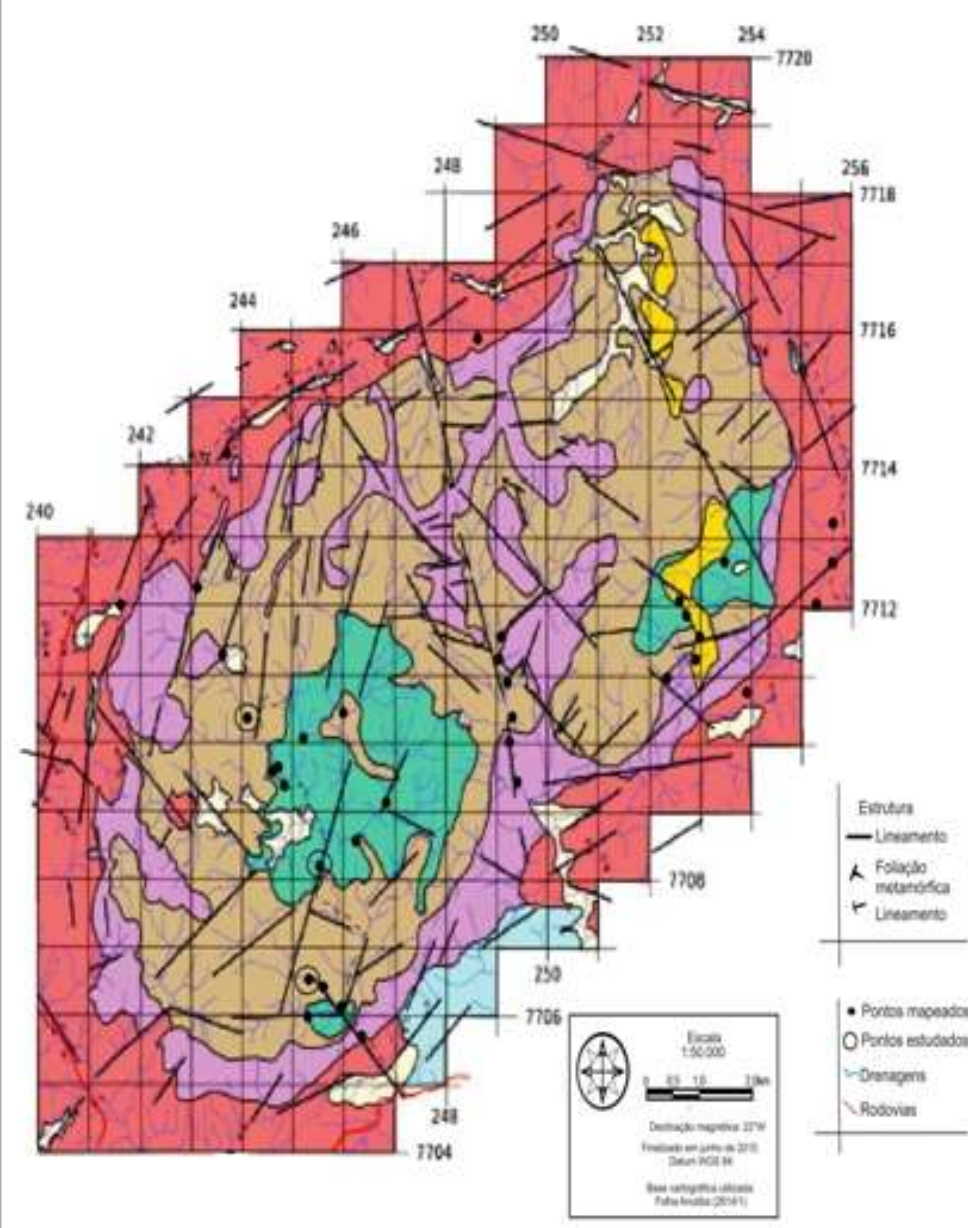

Unidades Ltodèrricas

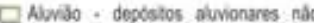

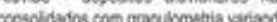
ente aroios grossas a anglas.

- Granto podritice of mertiz fina, tocha comsesta por quartzo, alopiodiaso, bionta

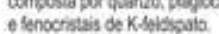

[D Hibrido - tocha de composiça granodoribca com lextura faneritica meds a goosa equiganuat oniunda de nistura entre o granito tanerilico crosso eogatro

- Ganilo taneritico grosso - rocha composta por quarizo. Ko.teldspato plagociasio, pocends conter alinita atessorios o poucos midicos. Apreserta tedura nequiganujar com ferocistas de K. Seltspato.

Basica poffróca - tocta de matriz fna.

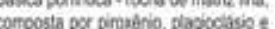
biotta com porferos de Kiledspiso.

E Gatro - rocha de composicto basiza cet

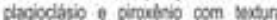
tenerica tha a grossa equigrandar.

$\square$ Grasse paranetandricos com grande quantidade de quartzo $e$, as vezes. presecrial de granida Pessu bindimento prassicoso contimentico a mentice.

$\square$ Grasse ofonelambrico - composio pur biotta, proculnio, plogiostsia, KAtelsoust: e pouco quartso

Figura 3 - Mapa Geológico do Complexo Intrusivo Santa Angélica e de suas rochas encaixantes (Adaptado de Nanni \& Chaves, 2011). Em destaque, estão os pontos mapeados nos quais foram coletadas as amostras analisadas neste artigo.

Segundo Bayer et al. (1987), o CISA intrude uma dobra antiforme constituída por paragnaisses do Complexo Paraíba do Sul e por ortognaisses granodioríticos a tonalíticos da Suíte G1, ambos localmente migmatizados e com foliação subvertical a vertical. O contato entre as rochas encaixantes e o CISA sugere que o mecanismo de intrusão ocorreu a partir de processos como o diapirismo, parcialmente controlados pelas zonas de cisalhamento (Weinberg et al., 2004 apud Campos et al., 2004).

\section{MIRMEQUITA: UMA BREVE REVISÃO BIBLIOGRÁFICA}

A mirmequita corresponde a um tipo de textura caracterizada pelo intercrescimento de plagioclásio sódico e quartzo vermicular próximo a bordas de cristais de plagioclásio e/ou de K-feldspato e entre o contato destes dois minerais (Turner and Verhoogen, 1960; Phillips, 1974; Cox et al., 1979 apud Collins, 1983).
O processo de formação da mirmequita pode ocorrer de diversas maneiras, dentre elas destacamse os processos metassomáticos envolvendo grãos de K-feldspato e íons de $\mathrm{Na}$ e Ca presentes na fase líquida (Becke, 1908 apud Barker, 1970), e a exsolução dos feldspatos (Harker, 1909 e Schwantke, 1909 apud Barker, 1970).

Nos processos metassomáticos, os íons de $\mathrm{K}$ do K-feldspato são substituídos por íons de $\mathrm{Ca}$ e $\mathrm{Na}$, o que resulta no intercrescimento vermicular de quartzo e plagioclásio em suas bordas (Figura 4). Esta hipótese se aplica a diversas rochas, tais como diorito e gabro.

O outro processo de formação da mirmequita ocorre a partir da exsolução de feldspatos originalmente homogêneos e ricos em $\mathrm{SiO}_{2}$. Para Schawantke (1909) (apud Barker, 1970), o feldspato envolvido nesta reação seria o K-feldspato. Collins (1997) acredita que a exsolução a partir do K- 
feldspato está associada ao ortoclásio que, em baixa temperatura e sob condições de stress, inverte para microclina e exsolve $\mathrm{Na}$ e $\mathrm{Ca}$ para a sua borda, formando assim a mirmequita.

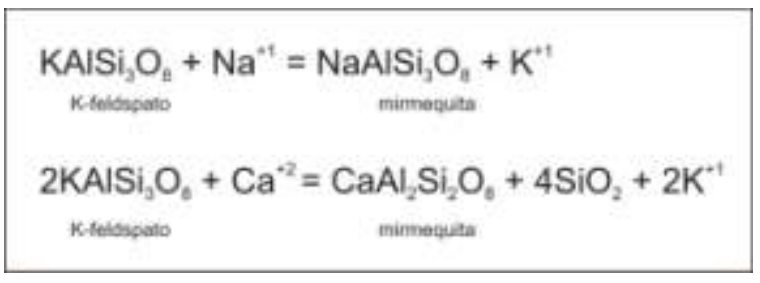

Figura 4 - Equação mostrando a reação que resulta na formação da mirmequita a partir de processos metassomáticos envolvendo íns de K, Ca e Na (Becke, 1908 apud Barker, 1970).

Apesar da complexidade dos processos, algumas características presentes nas rochas auxiliam a determinar a origem das mirmequita. Em gabro e dioritos, por exemplo, se o teor de Ca do plagioclásio presente na mirmequita for menor que o do Kfeldspato, o processo de exsolução não se aplica (Collins, 1996).

Muitas questões ainda estão em discussão sobre o processo de formação da mirmequita, que transcende as reações no estado sólido ocorrentes no final ou um pouco depois da cristalização magmática. Vernon (1991) destaca a ocorrência de mirmequita nas fraturas de grãos deformados de Kfeldspato e afirma que a formação deste tipo de textura também é favorecida por processos deformacionais que causam a nucleação da mirmequita e/ou contribui para o acesso de fluidos por fraturamento. Collins (1997) também afirma em seu trabalho sobre as rochas do Complexo Plutônico Alvand (Irã) que a quantidade de mirmequita formada a partir de metassomatismo tem uma relação com o grau de fraturamento e deformação dos grãos.

\section{MATERIAIS E MÉTODOS}

As informações sobre os aspectos geológicos da área de estudo foram obtidas através de levantamento bibliográfico de trabalhos anteriores complementado com a atividade de campo realizada pelos autores. Este trabalho de campo teve como objetivo a descrição geológica detalhada dos afloramentos-chave que expõem as interações ocorridas entre os magmas máficos e félsicos, com discriminação de suas feições diversas e coleta de amostras. As amostras utilizadas neste estudo foram coletadas a partir de três pontos descritos durante a atividade de campo (em destaque na figura 3 ).

Posteriormente, as amostras foram encaminhadas ao Laboratório de laminação do Instituto de Geociências da Universidade Federal de
Minas Gerais (UFMG) onde foram confeccionadas quatro seções polidas utilizadas no estudo petrográfico microscópico e nas análises em microssonda, sendo duas representantes do magma máfico tardio e duas da mistura de magmas (material híbrido), todas localizadas próximas aos principais contatos litológicos (gabro-granito e gabro-zona de mistura de magmas) da Suíte G5.

Para compreender os principais processos de desequilíbrio magmático que resultaram da inclusão destes xenocristais de feldspato potássico (oriundos de rochas graníticas) nestes litotipos foram analisados em microssonda eletrônica seis perfis traçados nas lâminas petrográficas durante o estudo petrográfico microscópio. Estes perfis iniciam-se entre o contato das bordas de reação com a rocha até chegar ao meio do xenocristal, de modo a analisar a variação mineralógica bem como o teor de diversos elementos, em especial o $\mathrm{Ca}$ e o $\mathrm{Na}$.

As análises em microssonda foram realizadas no Laboratório de Microanálise do Departamento de Física da UFMG, utilizando os seguintes padrões: $\mathrm{Na}_{2} \mathrm{O}$ - jadeíta, $\mathrm{K}_{2} \mathrm{O}$ - microclina, $\mathrm{AL}_{2} \mathrm{O}_{3}$ - anortita sintética, $\mathrm{SiO}_{2}$ - microclina, $\mathrm{MgO}$ - periclásio, $\mathrm{TiO}_{2}-$ rutilo, $\mathrm{FeO}$ - magnetita. Os resultados foram interpretados com o auxílio do programa MINPet Mineralogical and Petrological Data Processing System - versão 2.2 que permitiu determinar a classificação detalhada de cada ponto dos minerais analisados. A integração das microanálises químicas e do estudo petrográfico microscópico resultou no desenvolvimento de um modelo geológico que explica as possíveis reações entre xenocristais e o magma máfico e híbrido.

\section{RESULTADOS}

As rochas geradas a partir do magma máfico tardio são representadas pelas amostras M5F17 e MP19. Macroscopicamente, estes litotipos possuem cor preta, textura equigranular, além de apresentarem xenocristais de K-feldspato com bordas de reação (Figuras 5A e 5B). Segundo o estudo petrográfico microscópico, as amostras máficas tardias são constituídas essencialmente por plagioclásio, piroxênio (clinopiroxênio e ortopiroxênio), hornblenda, biotita e quartzo. Como minerais acessórios, têm-se a apatita e os minerais opacos. A proporção estimada de seus constituintes minerais possibilitou classificá-las no Diagrama de Streickeisen como gabro/diorito (Tabela 1 e Figura 6). Quanto aos aspectos texturais, ambas possuem granulação fina, porém os grãos da amostra MP19 são menores quando comparado à M5F17. 


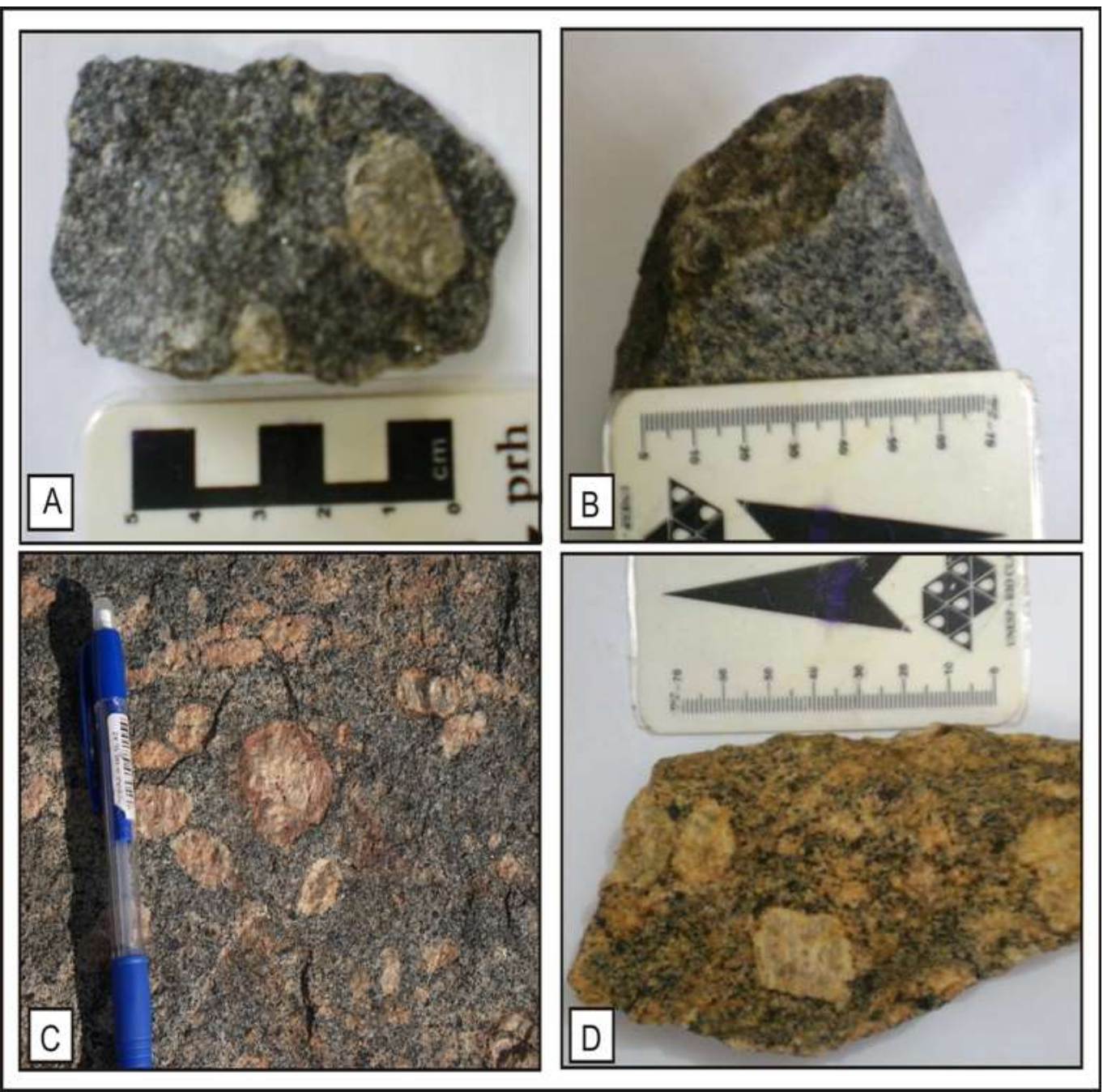

Figura 5 - Amostras representativas do magma máfico e do magma mixing. Legenda: A, M5F17; B, MP19; C, D5MIX23B; D, H5MIX23A.

As rochas geradas a partir magma mixing são representadas por duas amostras: D5MIX23B e H5MIN23A, ambas coletadas no mesmo ponto, porém em posições diferentes, e com xenocristais de K-feldspato com bordas de reação.

A amostra D5MIX23B (Figura 5C) tem cor cinza, é equigranular, com granulação predominantemente fina. A análise microscópica indicou a presença de plagioclásio, biotita, hornblenda, piroxênio e quartzo como minerais essenciais, além de apatita, minerais opacos e allanita como acessórios. De acordo com a composição modal, este litotipo é classificado como quartzo diorito/quartzo gabro (Tabela 1 e Figura 6).

Tabela 1 - Composição modal aproximada dos litotipos analisados, segundo o estudo petrográfico microscópico.

\begin{tabular}{|c|c|c|c|}
\hline \multicolumn{2}{|c|}{ Amostra M5F17 } & \multicolumn{2}{|c|}{ Amostra MP 19} \\
\hline Minerais & $\%$ & Minerais & $\%$ \\
\hline Plagioclásio & 70 & Plagioclásio & 70 \\
\hline Biotita & 8 & Biotita & 20 \\
\hline Piroxênio & 5 & Piroxênio & 6 \\
\hline Homblenda & 4 & Homblenda & 1 \\
\hline Quartzo & 2 & Quartzo & 1 \\
\hline Min. opacos & 1 & Min. opacos & 2 \\
\hline Apatita & 1 & Apatita & 1 \\
\hline
\end{tabular}

\begin{tabular}{|l|r|}
\hline \multicolumn{2}{|c|}{ Amostra D5MIX23B } \\
\hline \multicolumn{1}{|c|}{ Minerais } & $\%$ \\
\hline Plagioclásio & 70 \\
\hline Biotita & 10 \\
\hline Hornblenda & 8 \\
\hline Piroxènio & 6 \\
\hline Quartzo & 5 \\
\hline Min, opacos & 1 \\
\hline Apatita & 1 \\
\hline Alanita & 11 \\
\hline
\end{tabular}

\begin{tabular}{|l|r|}
\hline \multicolumn{2}{|c|}{ Amostra H5MIX23A } \\
\hline \multicolumn{1}{|c|}{ Minerais } & $\%$ \\
\hline Plagioclásio & 35 \\
\hline Microclina & 25 \\
\hline Quartzo & 15 \\
\hline Biotita & 5 \\
\hline Piroxénio & 4 \\
\hline Homblenda & 4 \\
\hline Min. opacos & 1 \\
\hline Alanita & 1 \\
\hline
\end{tabular}




\section{Diagrama QAP (Streickeisen, 1978)}
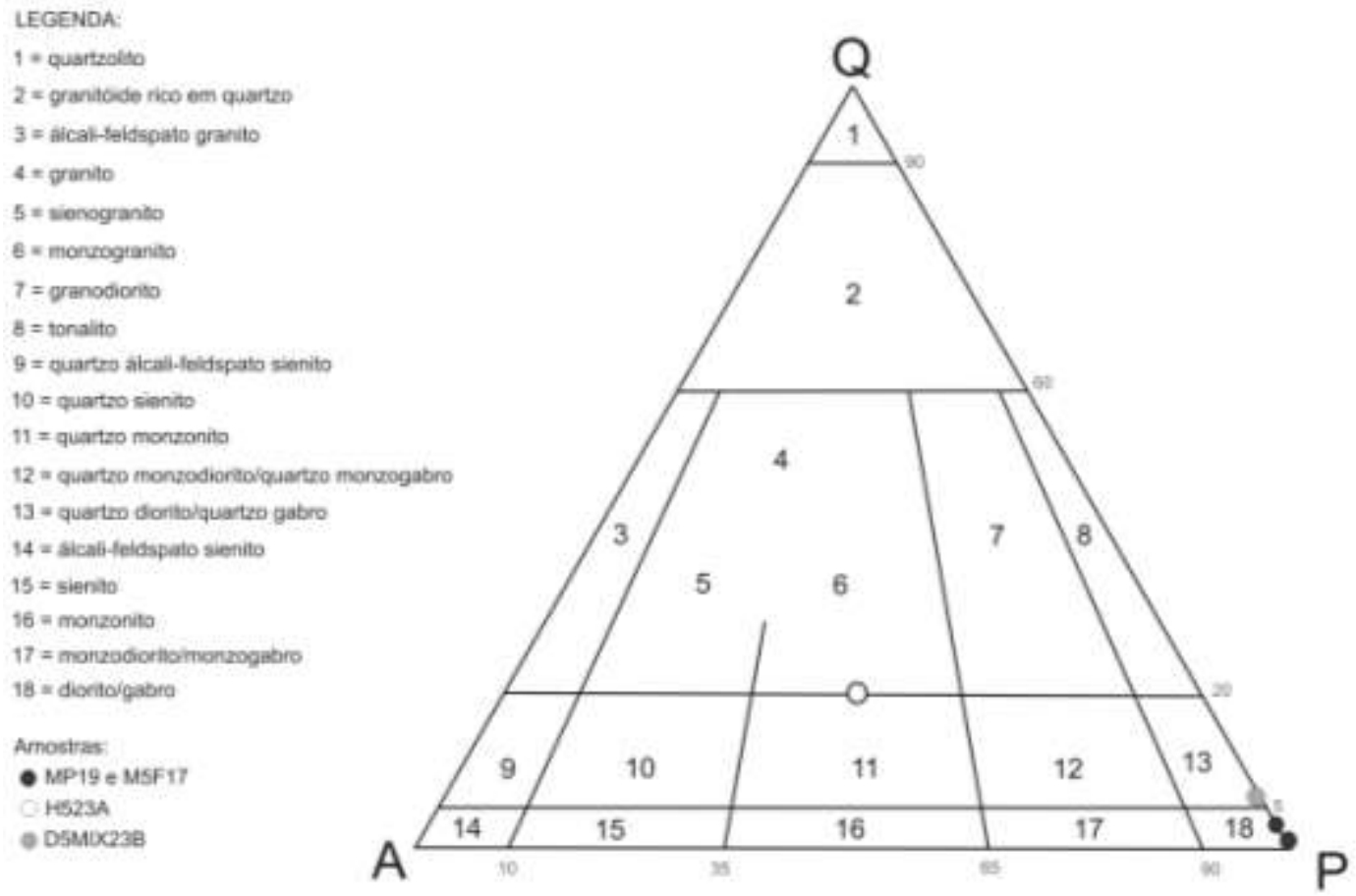

Figura 6 - Classificação das amostras estudadas segundo o diagrama QAP de Streickeisen (1978).

Apesar de fazer parte do magma mixing, a amostra H5MIN23A (Figura 5D) possui características distintas de D5MIX23B. Apresenta cor amarela acinzentada e textura equigranular, com granulação fina. Mineralogicamente é constituída essencialmente por plagioclásio, microclina, quartzo, biotita, piroxênio e hornblenda, sendo classificada no contato entre o monzogranito e o quartzo monzonito (Tabela 1 e Figura 6). Como minerais acessórios, foram encontrados grãos de apatita e de minerais opacos.

Os xenocristais de K-feldspato presentes nas amostras estudadas chegam a ter até $3 \mathrm{~cm}$ de comprimento, possuem hábito colunar, variam de euédricos a anédricos e comumente estão associados a muscovita e carbonatos. O estudo petrográfico indicou que a borda de reação presente nestes xenocristais é constituída exclusivamente por mirmequita (Figura 7), com exceção da amostra MP19, em que o único mineral encontrado nesta borda é o plagioclásio. Esta borda mirmequítica chega a ter até $3 \mathrm{~mm}$ de espessura, sendo caracterizada por vermes de quartzo inclusos em plagioclásio. Outra característica marcante é o padrão de fraturamento semelhante em todos os xenocristais, indicando que os mesmos foram deformados antes e/ou durante sua migração, possivelmente sobre influência da zona de cisalhamento descrita em trabalhos anteriores (Wiedemann et al, 1986; Bayer et al, 1987, Wiedemann et al, 1997). As fraturas encontram-se dispostas predominantemente paralelas entre si e comumente estão preenchidas por quartzo e são bordejadas por mirmequita e por pequenos grãos de plagioclásio (Figura 8).

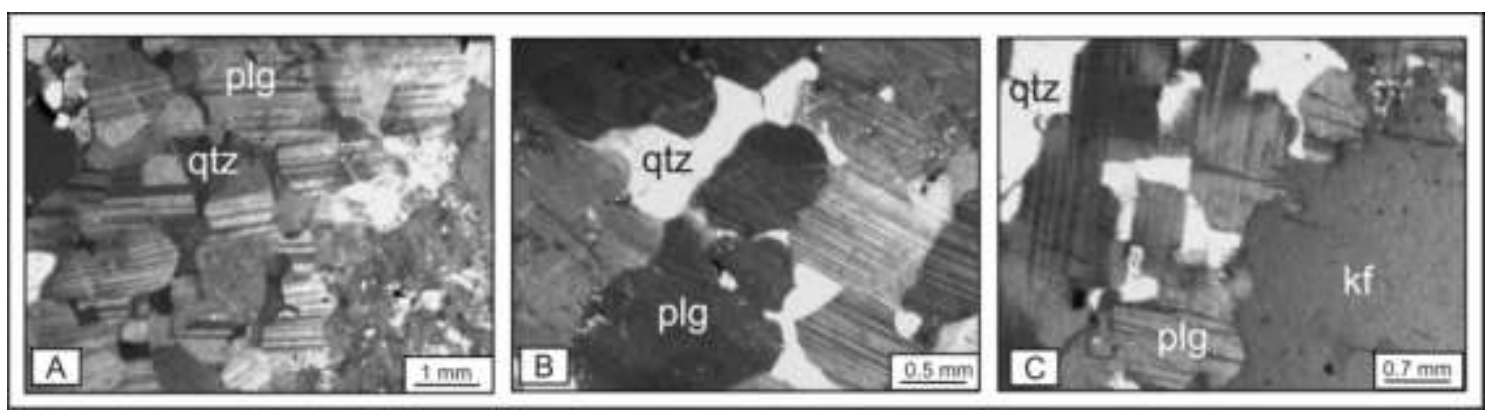

Figura 7 - Mirmequita na borda do K-feldspato: A e B, M5F17; C, D5MIX23B. Legenda: qtz, quartzo; plg, plagioclásio; kf, feldspato potássico. 

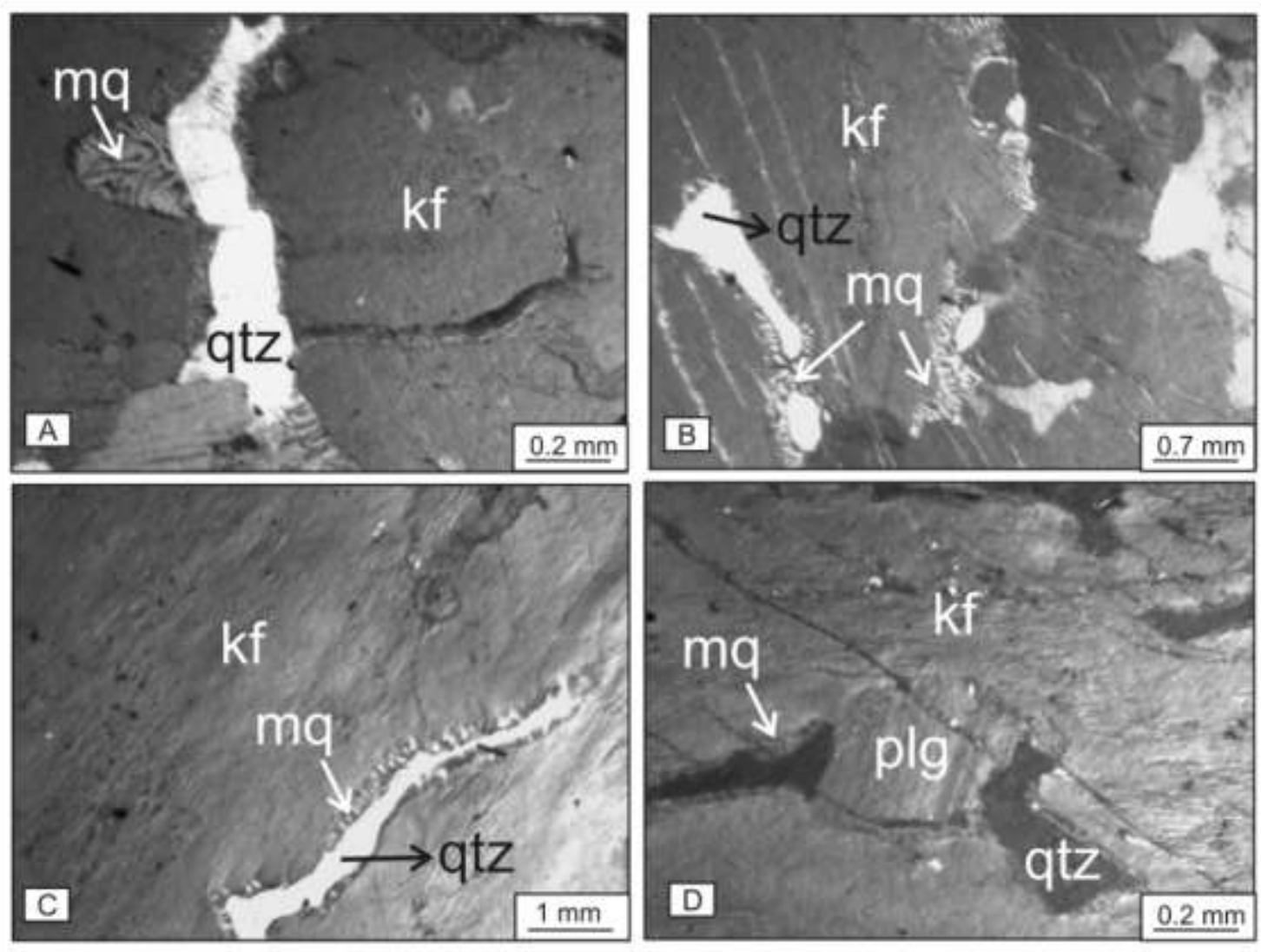

Figura 8 - Fraturas presentes nos xenocristais preenchidas por pequenos grãos de plagioclásio e por quartzo bordejadas por mirmequitas: $A$ e B, M5F17; C e D, D5MIX23B. Legenda: kf, feldspato potássico; qtz, quartzo; mq, mirmequita, plg, plagioclásio.

Buscando explicações para os processos que resultaram na geração destas bordas de reação mirmequíticas, foram realizadas análises em microssonda de perfis traçados a partir da borda até o centro dos xenocristais. As microanálises mostraram ser compatíveis com a mineralogia descrita a partir do estudo petrográfico.
A variação composicional dos feldspatos em cada um dos perfis analisados pela microssonda indica que houve uma variação dos teores de $\mathrm{Ca}$ e $\mathrm{Na}$. O teor de Ca é crescente da porção interna para a externa da mirmequita, enquanto que o teor de $\mathrm{Na}$ aumenta à medida que se aproxima do xenocristal (Tabela 2 e Figura 9).

Tabela 2 - Resultado das análises por microssonda dos perfis traçados da borda mirmequítica até o centro dos xenocristais de K-feldspato. $O$ ponto 1 corresponde ao ponto analisado mais próximo do contato borda de reação - rocha.

\begin{tabular}{|c|c|c|c|c|c|c|c|c|c|c|c|}
\hline No & $\mathrm{Na} 20$ & $\mathrm{~K} 20$ & Al203 & $\mathrm{CaO}$ & $\mathrm{SiO} 2$ & Total & Mineral & Cations & & \multicolumn{2}{|c|}{ teor anortita } \\
\hline MSF 17 & & & & & & & & $\mathrm{Ca}$ & $\mathrm{Na}$ & K & \\
\hline 1 & 6.85 & 0.29 & 24.71 & 636 & 6054 & 96.74 & PI & 1.222 & 2382 & 0.066 & 33 \\
\hline 2 & 6.92 & 0.36 & 2412 & 6.14 & 60.14 & 97.69 & PI & 1,193 & 2.439 & 0.083 & 32 \\
\hline 3 & 704 & 0.37 & 24.18 & 6.06 & 5980 & 97.45 & $\mathrm{PI}$ & 1.181 & 2483 & 0.086 & 31 \\
\hline 4 & 219 & 13.42 & 1885 & 0.18 & 64.44 & 99.07 & KF & 0.036 & 0.785 & 3.165 & 1 \\
\hline 5 & 1.34 & 14.71 & 18.79 & 0.12 & 63.59 & 98.55 & KF & 0.024 & 0.486 & 3.507 & 1 \\
\hline \multicolumn{12}{|c|}{ D5MDX23 } \\
\hline 1 & 7.10 & 0.34 & 2408 & 5.77 & 61,30 & 98.59 & PI & 1.109 & 2.469 & 0.078 & 30 \\
\hline 2 & 7.19 & 0.19 & 2405 & 571 & 61.10 & 9823 & $\mathrm{PI}$ & 1.1 & 2.507 & 0.044 & 30 \\
\hline 3 & 7.36 & 0.21 & 24.16 & 567 & 6141 & 98.80 & PI & 1.087 & 2553 & 0.048 & 29 \\
\hline 4 & 734 & 0.24 & 24.11 & 558 & 61.88 & 99.15 & PI & 1.065 & 2535 & 0.055 & 29 \\
\hline 5 & 743 & 0.19 & 24.20 & 5.42 & 6218 & 99.40 & $\mathrm{PI}$ & 1.031 & 2557 & 0.043 & 28 \\
\hline 6 & 1.34 & 14.42 & 18.78 & 0.06 & 63.56 & 98.17 & KF & 0.012 & 0.487 & 3.445 & 0 \\
\hline 7 & 324 & 11.06 & 1957 & 0.53 & 65.24 & 99.64 & KF & 0.103 & 1.143 & 2568 & 3 \\
\hline \multicolumn{12}{|c|}{ H5MIN23 } \\
\hline 1 & 769 & 0.20 & 2410 & 499 & 6432 & 101.29 & PI & 0.929 & 2591 & 0.044 & 26 \\
\hline 2 & 738 & 0.22 & 24.72 & 5.72 & 62.43 & 100.47 & PI & 1.078 & 2516 & 0.049 & 30 \\
\hline 3 & 7.68 & 0.30 & 24.24 & 491 & 6280 & 99.93 & PI & 0.928 & 2628 & 0.068 & 26 \\
\hline 4 & 7.76 & 0.20 & 2402 & 5. 10 & 6273 & 99.81 & PI & 0966 & 2.659 & 0.045 & 26 \\
\hline 5 & 821 & 0.15 & 23.60 & 433 & 6476 & 101.05 & PI & 0.807 & 2769 & 0.033 & 22 \\
\hline 6 & 868 & 0.15 & 2205 & 286 & 65.95 & 99.69 & $\mathrm{PI}$ & 0.537 & 2952 & 0.034 & 15 \\
\hline 7 & 0.87 & 15.78 & 1823 & 001 & 6232 & 9720 & KF & 0.001 & 0.322 & 3839 & 0 \\
\hline B & 4.49 & 934 & 1917 & 013 & 6810 & 10122 & KF & 0.026 & 1543 & 2112 & 1 \\
\hline
\end{tabular}




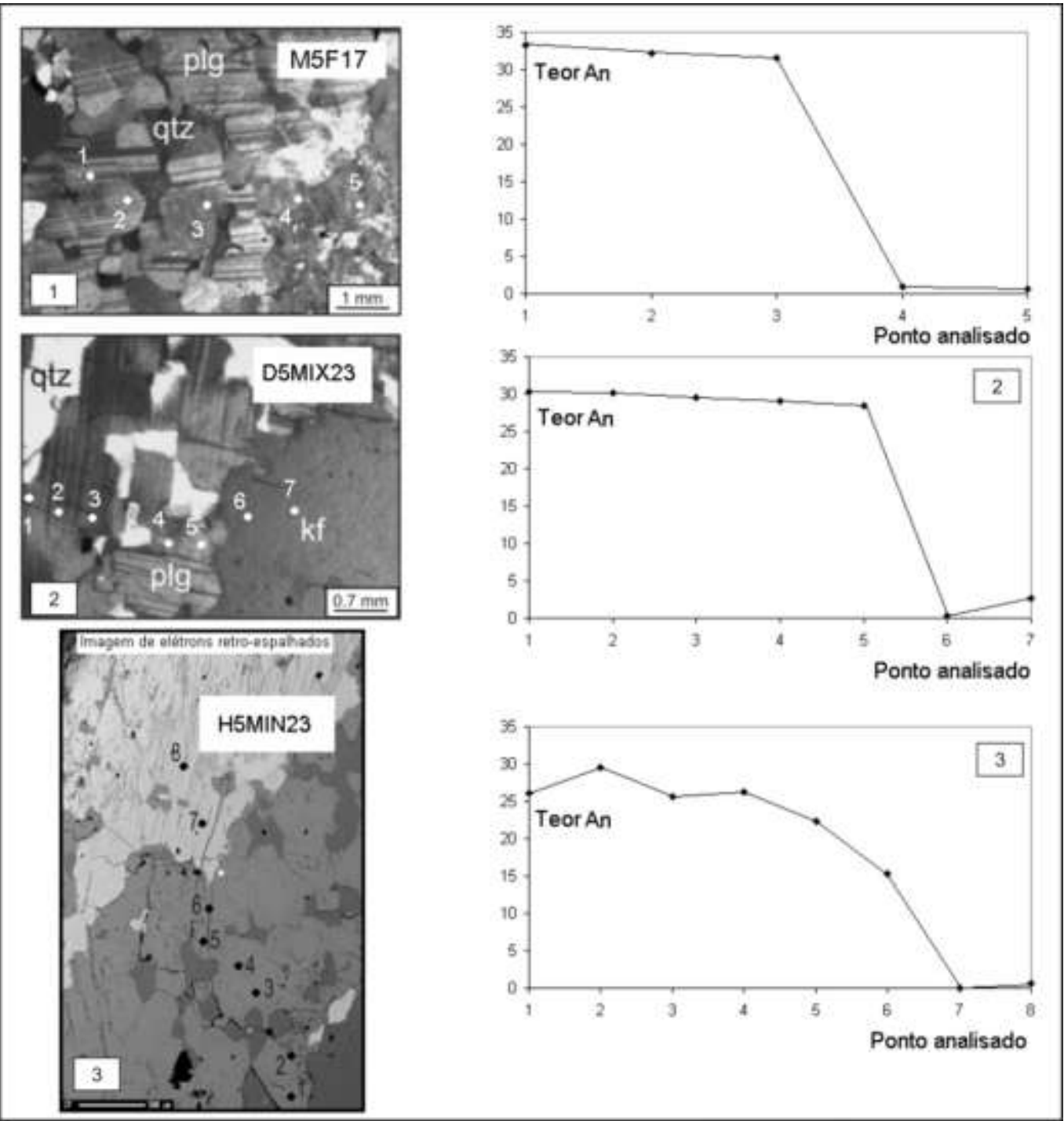

Figura 9 - Relação entre o teor de anortita e os pontos analisados na microssonda através do perfil traçado da borda de reação até o centro do xenocristal de K-feldspato das amostras H5MIN23A, D5MIX23B e M5F17.

\section{DISCUSSÃO E CONCLUSÃO}

A partir da integração do estudo petrográfico e das microanálises, conclui-se que a migração do feldspato potássico para as regiões máficas e de mistura de magmas ocorreu quando ambas ainda estavam em estado líquido, o que desencadeou uma reação entre o cristal (o K-feldspato) e os íons de Ca e $\mathrm{Na}$, presentes na fase líquida (Becke, 1908 apud Baker, 1970) (Figura 10).

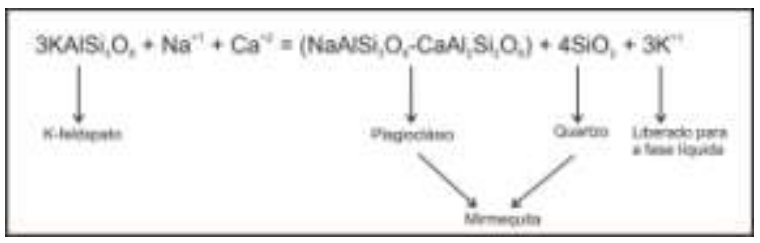

Figura 10 - Equação mostrando a reação xenocristal-líquido que desencadeou a formação de bordas mirmequíticas baseada na hipótese de Becke (adaptado de 1908 apud Baker, 1970).

Diferente de Schmidt-Thomé \& WeberDiefenbach (1987), que descreviam oligoclásio como único produto final da reação cristal-líquido, para a hipótese apresentada neste artigo, a reação resultou na formação da mirmequita nas bordas dos xenocristais.

As análises de microssonda mostraram que o teor de Ca é crescente da porção interna para a externa da mirmequita. Isto sugere que houve uma busca do equilíbrio do $\mathrm{Ca}$ da mirmequita com o $\mathrm{Ca}$ na fase líquida até cessar a reação.

As características químicas e mineralógicas indicam que estas reações desencadearam-se a partir de dois fatores condicionantes:

1 - Tempo de cristalização: a ausência de mirmequita nas bordas dos xenocristais da amostra MP19, esta com matriz mais fina (comparada às demais rochas), mostra que o processo de cristalização do magma deu-se de forma tão rápida que não houve tempo suficiente para ocorrer interação química capaz de formar uma borda mirmequítica. O único produto gerado a partir da 
reação cristal-líquido é o plagioclásio, que mesmo assim ocorre em quantidades pouco significantes (Figura 11).

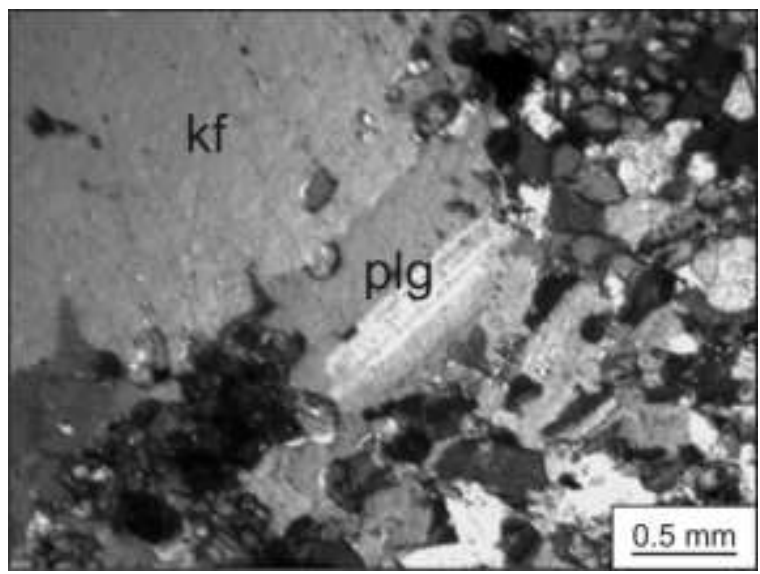

Figura 11 - Grão de plagioclásio na borda do K-feldspato (amostra MP19). Legenda: plg, plagioclásio; kf, feldspato potássico.

2 - Processos deformacionais: A presença de fraturas aumentou a superfície de contato entre o Kfeldspato e o material magmático, o que permitiu maior interação entre o líquido e as porções internas do mineral, tendo como produto final quartzo, comumente bordejado por mirmequitas, e plagioclásio preenchendo as fraturas.

Sendo assim, a mirmequita é produto do metassomatismo do K-feldspato envolvendo íons de Ca e Na. Neste caso, o componente sólido é representado pelo xenocristal, o fluido da reação corresponde ao material magmático que é fonte de íns de $\mathrm{Ca}$ e $\mathrm{Na}$. Apesar de a reação ser desencadeada em condições magmáticas (ou seja, durante o processo de cristalização), os processos deformacionais desempenharam papel importante, uma vez que a presença de fraturas favorece a circulação de fluidos e, consequentemente, a geração de mirmequita.

\section{AGRADECIMENTOS}

Agradecemos: ao Instituto de Geociências (IGC) da Universidade Federal de Minas Gerais (UFMG) por disponibilizar não só o transporte para a execução do trabalho de campo, mas também por preparar as seções polidas analisadas e discutidas neste trabalho; ao Departamento de Física, também da UFMG, juntamente ao IGC, por realizarem as análises em microssonda; e à Pró-Reitoria de Pesquisa (PRPq) - UFMG pelo auxílio financeiro o qual tornou possível o desenvolvimento deste artigo e também da dissertação de mestrado que envolve o tema aqui discutido.

\section{REFERÊNCIAS BIBLIOGRÁFICAS}

Alkmim, F.F., Marshak, S., Pedrosa-Soares, A.C., Peres, G.G., Cruz, S.C.P. \& Whittington, A. 2006. Kinematic evolution of the Araçuaí-West Congo orogen in Brazil and Africa: Nutcracker tectonics during the Neoproterozoic assembly of Gondwana. Precambrian Research, 149: 43 - 63.

Almeida F.F.M. 1977. O Cráton do São Francisco. Rev. Bras. Geoc. 7(4): 349 - 364.

Almeida, F.F.M., Hasui, Y., Rodrigues, E.P. \& Yamamoto, J. 1978. A Faixa de Dobramentos Araçuaí na região do Rio Pardo. In: SBG, $30^{\circ}$ Congresso Brasileiro de Geologia, Anais, 1: 270 283.

Almeida, F.F.M. \& Hasui, Y. (Eds) 1984. O Pré-Cambriano do Brasil. São Paulo, Edgard Blücher, 378 p.

Bayer B.; Schimidt-Thomé R.; Weber-Diefenbach K.; Horn H.A 1987. Complex concentric granitoid intrusions in the coastal mobile belt, Espírito Santo, Brazil: the Santa Angélica Pluton an example. Geologische Rubdschau, 76 (2): 357 - 371.

Bayer, P., Horn, H.A., Lammerer, B., Schmidt-Thomé, R., WeberDiefenbach, K., Wiedemann, C., 1986. The Brasiliano Mobile Belt in southern Espírito Santo (Brazil) and its igneous intrusions. Zentralblatt fu" $r$ Geologie und Palæontologie I. Heft 9/10, 1429-1440.

Barker, D.S. 1970. Granophyre, Myrmekite, and Graphic Granite. Geological Society of America Bulletin, 81: 3339 - 3350.

Brito-Neves, B.B., Cordani, U.G. 1991. Tectonic evolution of South America during the Late Proterozoic. Prec. Res., 53: 23-40.

Campos, C.M., Mendes, J.C., Ludka, I.P., Medeiros, S.R., Moura, J.C. \& Wallfass, C. 2004. A review of the Brasiliano magmatism in southern Espírito Santo, Brazil, with emphasis on postcollisional magmatism. Journal of the Virtual Explorer, 17(1), p.35, 2004.

Collins L.G. 1996. Citação de referencias e documentos eletrônicos. Disponível em: http:// http://www.csun.edu/ vcgeo005/index.html. Acessado em 4 de agosto de 2012.

Collins L.G. 1997. Citação de referencias e documentos eletrônicos. Disponível em: http://www.csun.edu/ vcgeo005/Nr4CaMyrm.pdf. Acessado em 4 de agosto de 2012.

Collins L.G. 1997. Citação de referencias e documentos eletrônicos. Disponível em: http://www.csun.edu/ vcgeo005/Nr5Exsolution.pdf. Acessoado em 4 de agosto de 2012.

Delgado I.M., Souza J.D., Silva L.C., Silveira Filho N.C., Santos R.A., Pedreira A.J., Guimarães J.T., Angelim L.A.A., Vasconcelos A.M., Gomes I.P., Lacerda Filho J.V., Valente C.R., Perrotta M.M. \& Heineck C.A. 2003. Geotectônica do Escudo Atlântico In: L.A. Bizzi, C. Shobbenhaus., R.M. Vidotti, J.H. Gonçalves (eds). Geologia, Tectônica e Recursos Minerais do Brasil, cap. V, p. : 227-334.

Ebert, H., Hasui, Y., 1998. Transpressional tectonics and strain partitioning during oblique collision between three plates in the Precambrian of southeast Brazil. In: Holdsworth, R.E., Stranchan, R.A., Dewey, J.F. (eds.). Continental transpressional and transtensional tectonics. Geol. Soc. London. Spec. Publ. 135, p.: 231-252.

Geobank - Serviço Geológico do Brasil [Internet]. Disponível em http://geobank.sa.cprm.gov.br/. Acessado em 9 de novembro de 2009.

Google Maps [Internet]. Disponível em: maps.google.com.br/. Acessado em 5 de maio de 2009.

Heilbron, M., Pedrosa-Soares, A.C., Campos-Neto, M.C., Silva, L.C., Trouw, R., Janasi, V.A. Província Mantiqueira. In: V. Mantesso-Neto, A. Bartorelli, C.D.R. Carneiro, B.B. BritoNeves (eds.), Geologia do Continente Sul-Americano. São Paulo, Editora Beca, cap. XIII, p. 203-234, 2004. 
Horn, A.H. 2006. Geologia da Folha Espera Feliz. Rio de Janeiro, CPRM - Serviço Geológico do Brasil, UFMG - Programa Geologia do Brasil, escala 1:100.000.

IBGE - Instituto Brasileiro de Geografia e Estatística. 1978. Anutiba (ES) - Folha SD-24-V-A-V-1. Anutiba, Mapa Topográfico, escala 1:50.000

Inda, H.A.V. \& Barbosa, J. 1978. Mapa Geológico do Estado da Bahia, Texto Explicativo. Salvador, Secretaria de Minas e Energia, Coordenação da Produção Mineral, 122 p.

Machado, N., Valladares, C., Heilbron, M., Valeriano, C., 1996. U$\mathrm{Pb}$ geocronology of the central Ribeira Belt (Brazil) and implications for the evolution of the Brazilian Orogeny. Prec. Res., 79: 347-361.

Marshak, S., Alkmim, F.F., Whittington, A. \& Pedrosa-Soares, A.C. 2006. Extensional collapse in the Neoproterozoic Araçuai orogen, eastern Brazil: A setting for reactivation of asymmetric crenulation cleavage. Journal Structural Geology 28: 129- 147 .

Martins, V.T.S., Teixeira, W., Noce, C.M. \& Pedrosa-Soares, A.C. 2004. Sr and Nd characteristics of Brasiliano-Pan African granitoid plutons of the Araçuaí orogen, southeastern Brazil: Tectonic implications. Gondwana Research, 7: 75-8.

Medeiros, S.R., Wiedemann, C. \& Vriend, S. 2001. Evidence of mingling between contrasting magmas in a deep plutonic environment: the example of Várzea Alegre, In the PanAfrica/ Brasiliano Mobile Belt in Brazil. Anais Academia Brasileira Ciências, 73: 99-119.

Mendes, J.C., Medeiros, S.R. \& McReath, I. 2005. CambroOrdovician Magmatism in SE Brazil: U-Pb and Rb-Sr Ages, Combined with $\mathrm{Sr}$ and $\mathrm{Nd}$ isotopic data of charnockitic rocks from Várzea Alegre Complex. Gondwana Research, 8: $337-$ 349.

Meneses P. R., Paradella W. R. 1978. Síntese geológica preliminar da parte sul do Estado do Espírito Santo. In: SIMPÓSIO BRASILEIRO DE SENSORIAMENTO REMOTO, INPE/ CNPq, São José dos Campos (SP). Anais, 479 - 499.

Nalini, H.A., Bilal, E., Paquette, J.L., Pin, C. \& Machado, R. 2000. Geochronologie $\mathrm{U}-\mathrm{Pb}$ et géochimie isotopique $\mathrm{Sr}-\mathrm{Nd}$ des granitoides neoproterozoiques des suites Galileia et Urucum, vallée du Rio Doce, Sud-Est du Brésil. Compte Rendu Academie Science Paris, 331: 459-466.

Nalini, H. A., Bilal, E. \& Correia-Neves, J.M. 2000. Syncollisional peraluminous magmatism in the Rio Doce region: mineralogy, geochemistry and isotopic data of the Urucum suite (eastern Minas Gerais State, Brazil). Rev. Bras. Geoc., 30: 120-125.

Nalini, H.A., Machado, R.M. \& Bilal, E. 2005. Geoquímica e petrogênese da Suíte Galiléia: exemplo de magmatismo tipoI, metaluminoso, pré-colisional, neoproterozóico, da região do Médio Vale do Rio Doce. Rev. Bras. Geoc., 35 (4suplemento): 23-34.

Nanni, A.S. \& Chaves, A.O. 2011. Uso de aplicativos computacionais livres em disciplinas de mapeamento geológico. GeoFocus (Informes y comentários), 11, 55 - 65.

Noce C.M.; Macambira M.J.; Pedrosa-Soares A.C. 2000 Chornology of Neoproterozóico-Cambrian granitic magmatism in the Araçuaí Belt, eastern Brazil, based on single zircon evaporation dating. Rev. Bras. Geoc., 30: 25-29.

Noce C.M.; Pedrosa-Soares A.C.; Silva L.C. \& Alkmim. 2007. O embasamento arqueano e paleoproterozóico do Orógeno Araçuaí. Geonomos, 15(1): 17 - 23.

Pedrosa-Soares A.C.; Wiedemann C.M.; Fernandes M.J.S.; Faria L.F.; Ferreira J.C.H. 1999. Geotectonic significance of the Neoproterozoic granitic magmatism in the Araçuaí Belt, eastern Brazil: a model and pertinent questions. Rev. Bras. Geoc.,29(1): 59 - 66

Pedrosa-Soares, A.C. \& Wiedemann-Leonardos.2000. Evolution of the Araçuaí Belt and its connection to the Ribeira Belt, eastern Brazil. In: U.G Cordani, E.J. Milani, A. Thomaz-Filho, D.A. Campos, D.A. (orgs), Tectonic Evolution of South America. SBG, São Paulo, p. 265-285.

Pedrosa-Soares A.C.; Noce C.M.; Wiedemann C.M. \& Pinto C.P. 2001. The Araçuaí-West Congo orogen in Brazil: An overview of a confined orogen formed during Gondwanland assembly. Precambrian Research, 110: 307-323.

Pedrosa-Soares A.C.; Castañeda C.; Queiroga G.; Gradim C.; Belém J.; Roncato J.; Novo T.; Dias P.; Gradim D.; Medeiros S.; Jacobsohn T.; Babinski M. \& Vieira V. 2006. Magmatismo e tectônica do Orógeno Araçuaí no Espírito Santo $\left(18^{\circ}-19^{\circ}\right.$, $\left.41^{\circ}-40^{\circ} 30^{\prime} \mathrm{W}\right)$. Geonomos 16: 97 - 111.

Pedrosa-Soares A.C.; Noce C.M.; Alkmim F.F.; Silva L.C.; Babinski M.; Cordani U.; Castañeda C. 2007. Orógeno Araçuaí: Síntese do conhecimento 30 anos após Almeida. Geonomos, 15(1): $01-16$.

Pedrosa-Soares A.C.; Roncato J.; Castañeda C.; Queiroga G.; Belém J.; Gradim C.; Novo T.; Dias A.H.A.; Gradim D.; Medeiros S.; Jacobsohn T.; Costa A.G. 2008. Geologia e recursos minerais da região coberta pelas folhas Ecoporanga, Mantena, Montanha e Nova Venécia - ES (Programa Geologia do Brasil, contrato CPRM-UFMG). In: SBG, $44^{\circ}$ Congresso Brasileiro de Geologia, Anais, p.11.

Pinto, C.P., Drumond, J.B.V., Féboli, W.L. (eds.). 1997. Projeto Leste, Etapa 1. CPRM-COMIG, Belo Horizonte.

Pinto, C.P., Drumond, J.B.V., Féboli, W.L. (coord.) 2001. Projeto Leste, Etapas 1 e 2. CPRM-COMIG, Belo Horizonte, CDROM.

Schmidt-Thomé, R., 1987. Der Santa Angelica Pluton im AraçuaíRibeira Mobile Belt, südliches Espírito Santo, Brasilien: Magmenmischung in einem invers zonierten Pluton. Unpub. PhD Thesis. Ludwig-Maximilians-Universität, München, $191 \mathrm{pp}$.

Schmidt-Thomé, R. and Weber-Diefenbach, K., 1987. Evidence for frozen-in magma mixing in Brasiliano calc-alkaline intrusions. The Santa Angélica pluton, southern Espírito Santo, Brazil. Rev. Bras. Geoc., 17: 498-506.

Schobbenhaus, C., Campos, D.A., Derze, G.R. \& Asmus, H.E. 1984. Geologia do Brasil. Brasília, DNPM, 501 p.

Siga-Júnior, O., Teixeira, W.; Cordani, U.G., Kawashita, K. \& Delhal, J. 1982. O padrão geológico-geocronológico das rochas de alto grau da parte setentrional da faixa Ribeira a norte do Rio de Janeiro, Brasil. In: Congresso Latinoamericano Geologia, 5, Argentina. Actas, 1, 349-370.

Silva L.C.; Armstrong R.; Noce A.C.; Carneiro M.A.; Pimentel M.; Pedrosa-Soares A.C.; Leite C.A.; Vieira V.S.; Silva M.A.; Paes V.J.C. \& Cardoso Filho J.M. 2002. Reavaliação da evolução geológica em terrenos pré-cambrianos brasileiros com base em novos dados U-Pb SHIMP, parte II: Orógeno Araçuaí, cinturão mineiro e Cráton São Francisco Meridional. Rev. Bras. Geoc., 32(4): 513 - 528.

Silva, L.C., McNaughton, N.J., Armstrong, R., Hartmann, L. \& Fletcher, I. 2005. The Neoproterozoic Mantiqueira Province and its African connections. Precambrian Research, 136: 203240.

Silva L.C.; Pedrosa-Soares A.C.; Noce C.M.; Pinto C.P.; Gomes A.C.B.; Baltazar O.F.; Vieira V.S.; Queiroga G.; Armstrong R. 2008. Do magmatismo pré-orogênico ao colapso do Orógeno: a complexa sucessão magmática no Orógeno Araçuaí. In: SBG, $44^{\circ}$ Congresso Brasileiro de Geologia, Anais, p.11. 
Streckeisen, A. L., 1978. IUGS Subcommission on the Systematics of Igneous Rocks. Classification and Nomenclature of Volcanic Rocks, Lamprophyres, Carbonatites and Melilite Rocks. Recommendations and Suggestions. Neues Jahrbuch für Mineralogie, Abhandlungen, Vol. 141, 1-14.

Tupinambá, M.; Heilbron, M.; Duarte, B..P.; Nougueira, J.R.;Valladares, C.; Almeida, J.; Silva, L.G.E.; Medeiros, S.R.; Almeida, C.G.; Miranda, A.; Ragatky, C.D.; Mendes, J.; Ludka, I. 2007. Geologia da Faixa Ribeira Setentrional: Estado da arte e conexões com a Faixa Araçuaí. Geonomos, 15(1): 67 - 79.

Vernon, R.H. 1991. Questions about myrmekite in deformed rocks. Journal of Strutural Geology, 2: 979-985.

Whittington A.G., Connelly J., Pedrosa-Soares A.C., Marshak S. \& Alkmim F.F. 2001. Collapse and melting in a confined orogenic belt: Preliminary results from the Neoproterozoic Araçuaí belt of eastern Brazil. In: American Geophysical Union Meeting, 2001,

Wiedemann, C., 1993. The evolution of the early Paleozoic, late to post-collisional magmatic arc of the Coastal Mobile Belt, in the State of Espírito Santo, eastern Brazil. Anais da Academia Brasileira de Ciências, 65: 163-181.

WIEDEMANN, C.M.; PENHA, H.M.; SCMIDT-THOME, R. 1987. Granitóides do Espírito Santo and Rio de Janeiro States. Rev. Bras. Geoc., 17(4): 674 - 689.
Wiedemann, C.M., Bayer, P., Horn, H., Lammerer, B., Ludka, I.P., Schmidt-Thomé, R. and Weber-Diefenbach, K., 1986. Maciços intrusivos do sul do Espírito Santo e seu contexto regional. Rev. Bras. Geoc., 16: 24-37.

Wiedemann, C., Mendes, J.C., Moura, J.C., Costa Nascimento, R.C. and Ludka, I.P., 1997. Granitoids of the Espírito Santo Magmatic Arc. In: International Symposium on Granites and Associated Mineralizations, 2, ISGAM, Salvador, Excursions Guide, pp. 57-76.

Wiedemann, C.M., Medeiros, S.R., Mendes, J.C., Ludka, I.P., Moura, J.C. 2002. Architecture of Late Orogenic Plutons in the Aracuaí-Ribeira Folded Belt, Southeast Brazil. Gondwana Research, 5(2): 381 - 399.

Wiedemann-Leonardos C.M.; Ludka I.P.; Medeiros S.R., Mendes J.C.; Costa-de-Moura J. 2000. Arquitetura de plutons zonados da Faixa Araçuaí-Ribeira. Geonomos, 15(1): 25 - 38.

Zanon M. 2010. Geologia e petrografia da porção ocidental do Maciço Santa Angélica, ES: contribuições para a lavra de rochas ornamentais. Monografia de Graduação, Departamento de Geociências, Universidade Federal Rural do Rio de Janeiro. 